\title{
Block fields and block streams deposits in the Pirin Mountains
}

\section{Наслаги в каменни морета и каменни реки в Пирин планина}

\author{
Alexandar Sarafov ${ }^{1}$, Dimitar Krenchev ${ }^{2}$ \\ Александър Сарафов ${ }^{1}$, Димитър Кренчев

\begin{abstract}
${ }^{1}$ Sofia University “St. Kliment Ohridski”, Faculty of Geology and Geography, Department of Landscape Ecology and Environmental Protection, 15 Tsar Osvoboditel Blvd., 1504 Sofia; E-mail: saraffov@gea.uni-sofia.bg

${ }^{2}$ Sofia University “St. Kliment Ohridski”, Faculty of Geology and Geography, Department of Climatology, Hydrology and Geomorphology, 15 Tsar Osvoboditel Blvd., 1504 Sofia; E-mail: dkrenchev@gea.uni-sofia.bg
\end{abstract}

\begin{abstract}
The block fields and block streams are widespread in the Pirin Mountains. They are significant in size and are distributed on both relatively flat and sloping surfaces. Their origin is associated with frost weathering, which can subsequently be supplemented by other processes related to the destruction of the material - chemical weathering, fluvial, cryogenic processes, etc. The main aim of the study is to analyze the block field and block stream deposits which will give us a better understanding of their origin and evolution.
\end{abstract}

Keywords: block fields, block streams, deposits, Pirin Mountains, geomorphological study.

В геоморфоложката литература каменните морета (block field, stone field, rubble sheet) ce pazглеждат като обширни пространства, заети с големи и средни по размер скални блокове, съставляващи поне 50\% от техните наслаги, разположени както върху мальк, така и върху по-голям наклон на склона (Sharpe, 1938; Caine, 1968; Piirola, 1969; Washburn, 1979). Каменните реки (block streams, stone runs) се дефинират като дълги и тесни линейно ориентирани по посока на наклона акумулативни форми като разрушените материали в тях нямат връзка директно с рушащ се скален откос или срутище (Washburn, 1979).

В българската литература първият, който ги дефинира и започва изследването им е Гловня (Glovnia, 1958, 1962, 1968). Той ги разглежда в посочения контекст, но прави уговорката, че каменните морета могат да са разположени както на равни, така и на наклонени повърхнини с овална и линейна форма, а каменни реки той намира само на Витоша. Гловня твърди, че двете форми са резултат от геокриоложките процеси и следователно се срещат в Рила и Пирин, но всичките му изследвания касаят само Рила. След Гловня единици са авторите, които споменават посочените форми.

В настоящата публикация се коментират резултатите, получени от няколко участька в Пирин (фиг. 1):
- Суходолски циркус - изследвани са каменно море (т. 826 на височина 2240 m) и каменна река (т. 828 на $2334 \mathrm{~m}$ ). Двете форми са върху склонове с наклон 20-22

- Бъндеришки циркус - изследвани са каменно море (т. 829 на 2010 m върху склон с наклон около $20^{\circ}$ ) и каменна река (т. 832 на 2050 m върху наклон в горната част от $30^{\circ}$, в средната $24^{\circ}$ и в долната $\left.20^{\circ}\right)$;

- Безбожки циркус - две каменни морета на височина 2270 (т. 005) и на 2280 m (т. 006), разположени съответно върху склонове с наклон от $5^{\circ}$ до $45^{\circ}$.

Чрез морфоскопски анализ на едрите късове (Wentworth, 1922; Serebrianniy, 1980) са измерени общо 310 бр. къса от две петрографски разновидности: гранити и мрамори (Marinova, Zagorchev, 1990). Мраморите изграждат част от каменното море в Суходолския циркус, а всички останали са от гранити.

В каменното море на Суходолския циркус са разграничени на основата на големината на късовете, горна и долна част (табл. 1). В горната част големината показа фракции от дребен блокаж и едър чакъл, а долната част бе съставена от среден и едър блокаж. Установи се и относително голям брой на счупени късове. Изследванията върху петрографския състав показаха, че гранитните и мраморни късове имат близки стойности на заобленост и размери. Ние свърз- 

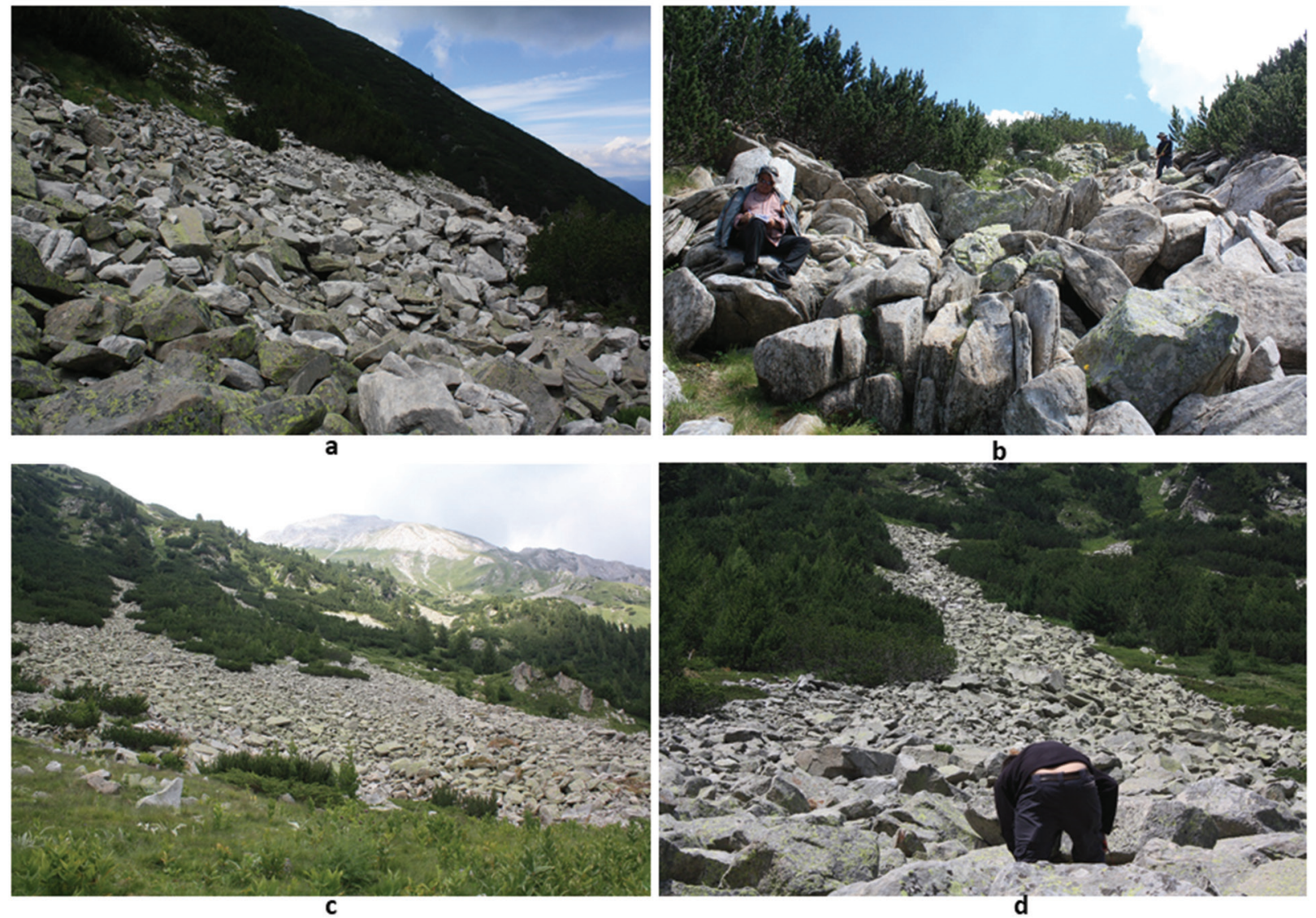

Фиг. 1. Част от изследваните ключови участъци: $a$ - каменно море в Суходолски циркус; $b$ - каменна река Суходолски циркус; $c$ - каменно море в Бъндеришки циркус; $d$ - каменна река в Бъндеришки циркус

ваме късовете от горната част с процеси на изветряне на основните скали, докато в долната част изветрянето е на отделните блокове. Формата им дава основание да се приеме слаб транспорт чрез преобръщане. Всичко това потвърждава и различното време на образуване (респ. изветряне на късовете). Горната част показва по-млада възраст (предполагаме холоцен), докато долната част би могла да бъде от късноледниково време). За разлика от каменното море, реката в Суходолския циркус е изградена от огладени in situ до 3-та степен късове, заобленост, която е характерна за гранитите.

Подобна закономерност бе отбелязана и в каменната река на Бъндеришкия циркус, където в средната част бяха отбелязани най-едрите късове, нещо, което е резултат от слаба промяна в наклона на склона (от $30^{\circ}$ към $24^{\circ}$ ). Последната е предизвикала и придвижване на късовете, което е станало чрез претъркулване в горната и средна част и влачене в средната. Вероятно скоростите на тези движения не са били високи, защото счупеният чакъл не надхвърля 7\%.

Каменното море в същия циркус (т. 832) е разположено в подножните части на левия до- линен склон на р. Бъндерица. Наблюдава се и сходство по отношение на големината и общата огладеност на късовете в каменното море и ниската (долна) част на каменната река.

В Безбожкия циркус каменните морета са разположени на приблизително еднаква надморска височина под вр. Безбог, но на склонове с различна експозиция - т. 005 е на южна, а т. 006 е на северозападна експозиция. При каменно море т. 005 преобладават късовете от фракцията на средния и едрия блокаж, докато при участьк 006 те са с размери на дребен блокаж и едър чакъл. Няма признаци за движение на късовете.

В обобщение, каменните реки и морета доминират над горната граница на гората, но са разпространи и в горския пояс. В изследваните участьци са отбелязани различия в размерите на късовете и тяхната огладеност. Най-едри (а ние предполагаме, че са и най-стари) са късовете в ниските части на каменните морета и реки. Местоположението на тези части свързваме с долинните подножия. Във височина огладеността намалява. Отбелязаният слаб транспорт е бил както чрез салтиране, така и чрез влачене. Там, където наклонът на склонове е около $30^{\circ}$, преоб- 
Таблица 1. Резултати от морфоскопския анализ на изследваните каменни реки и морета

\begin{tabular}{|c|c|c|c|c|c|c|c|c|c|}
\hline & \multicolumn{2}{|c|}{ T. 826} & \multirow[b]{2}{*}{ T. 828} & \multicolumn{3}{|c|}{ T. 829} & \multirow[b]{2}{*}{ T. 832} & \multirow[b]{2}{*}{ T. 005} & \multirow[b]{2}{*}{ T. 006} \\
\hline & $\begin{array}{c}\text { горна } \\
\text { част }\end{array}$ & $\begin{array}{c}\text { долна } \\
\text { част }\end{array}$ & & $\begin{array}{l}\text { горна } \\
\text { част }\end{array}$ & $\begin{array}{l}\text { средна } \\
\text { част }\end{array}$ & $\begin{array}{c}\text { долна } \\
\text { част }\end{array}$ & & & \\
\hline $\begin{array}{l}\text { Брой на } \\
\text { измерените } \\
\text { късове в } \\
\text { проба }\end{array}$ & 30 & 40 & 30 & 50 & 30 & 30 & 40 & 30 & 30 \\
\hline $\begin{array}{l}\text { Най-малки } \\
\text { стойности } \\
(\mathrm{cm}) \\
\end{array}$ & $\begin{array}{l}\mathrm{a}-11, \\
\mathrm{~b}-5 \\
\mathrm{c}-3\end{array}$ & $\begin{array}{c}\mathrm{a}-10 \\
\mathrm{~b}-9 \\
\mathrm{c}-3\end{array}$ & $\begin{array}{l}\mathrm{a}-39, \\
\mathrm{~b}-25, \\
\mathrm{c}-15\end{array}$ & $\begin{array}{l}\mathrm{a}-15 \\
\mathrm{~b}-8 \\
\mathrm{c}-3\end{array}$ & $\begin{array}{l}\mathrm{a}-40, \\
\mathrm{~b}-24, \\
\mathrm{c}-16 \\
\end{array}$ & $\begin{array}{c}\mathrm{a}-31 \\
\mathrm{~b}-27 \\
\mathrm{c}-8 \\
\end{array}$ & $\begin{array}{l}\mathrm{a}-14 \\
\mathrm{~b}-9 \\
\mathrm{c}-3 \\
\end{array}$ & $\begin{array}{l}a-13, \\
b-6,5 \\
c-4,5 \\
\end{array}$ & $\begin{array}{l}\mathrm{a}-6,7, \\
\mathrm{~b}-4,8, \\
\mathrm{c}-2,6\end{array}$ \\
\hline $\begin{array}{l}\text { Най-големи } \\
\text { стойности } \\
(\mathrm{cm}) \\
\end{array}$ & $\begin{array}{l}\text { a-140, } \\
\text { b- } 83, \\
\text { c-32 }\end{array}$ & $\begin{array}{l}\text { a-295, } \\
\text { b-193, } \\
c-144\end{array}$ & $\begin{array}{l}\text { a-190, } \\
\text { b-160, } \\
c-116\end{array}$ & $\begin{array}{c}\text { a-113, } \\
\text { b- } 76, \\
c-35\end{array}$ & $\begin{array}{c}\text { a- } 260 \\
\text { b- } 190 \\
\text { c- } 86\end{array}$ & $\begin{array}{c}\text { a-182, } \\
\text { b-143, } \\
\text { c-93 }\end{array}$ & $\begin{array}{c}\text { a- } 180, \\
\text { b- } 153, \\
c-56\end{array}$ & $\begin{array}{c}\text { a-176, } \\
\text { b- } 142, \\
\text { c- } 68\end{array}$ & $\begin{array}{c}\mathrm{a}-120, \\
\mathrm{~b}-64 \\
\mathrm{c}-33\end{array}$ \\
\hline $\begin{array}{l}\text { Средно } \\
\text { аритметично } \\
(\mathrm{cm}) \\
\end{array}$ & $\begin{array}{l}\mathrm{a}-40 \\
\mathrm{~b}-20 \\
\mathrm{c}-12 \\
\end{array}$ & $\begin{array}{l}\text { a- } 84, \\
\text { b-57, } \\
\text { c-34 }\end{array}$ & $\begin{array}{l}\text { a-113, } \\
\text { b- } 81, \\
\text { c-48 }\end{array}$ & $\begin{array}{l}\mathrm{a}-40, \\
\mathrm{~b}-24, \\
\mathrm{c}-13\end{array}$ & $\begin{array}{l}\mathrm{a}-119, \\
\mathrm{~b}-76 \\
\mathrm{c}-44\end{array}$ & $\begin{array}{l}a-82, \\
b-57 \\
c-32 \\
\end{array}$ & $\begin{array}{l}\text { a-73, } \\
\text { b-49, } \\
\text { c- } 28 \\
\end{array}$ & $\begin{array}{l}a-61, \\
b-40, \\
c-21,2 \\
\end{array}$ & $\begin{array}{c}\text { a-20,4, } \\
\text { b-12,8, } \\
c-7,5 \\
\end{array}$ \\
\hline $\begin{array}{l}\text { Стандартно } \\
\text { отклонение } \\
(\mathrm{cm}) \\
\end{array}$ & $\begin{array}{c}\text { a-31, } \\
\text { b-17, } \\
\text { c-7 }\end{array}$ & $\begin{array}{l}a-54 \\
b-36 \\
c-25\end{array}$ & $\begin{array}{l}\text { a-39, } \\
\text { b-35, } \\
c-24\end{array}$ & $\begin{array}{c}\mathrm{a}-23, \\
\mathrm{~b}-15 \\
\mathrm{c}-7\end{array}$ & $\begin{array}{l}\text { a-61, } \\
\text { b-37, } \\
\text { c-22 }\end{array}$ & $\begin{array}{l}a-42 \\
b-32 \\
c-15\end{array}$ & $\begin{array}{l}\mathrm{a}-38, \\
\mathrm{~b}-31 \\
\mathrm{c}-14\end{array}$ & $\begin{array}{c}\text { a-48,2, } \\
\text { b-33,1, } \\
\text { c-4,4 }\end{array}$ & $\begin{array}{c}\text { a-27,4, } \\
\text { b- } 15,7, \\
\text { c- } 8,2\end{array}$ \\
\hline $\begin{array}{l}\text { Обща } \\
\text { огладеност }\end{array}$ & 1 & 1,75 & 2,37 & 0,98 & 1,53 & 1,93 & 1,38 & 1,23 & 0,89 \\
\hline $\begin{array}{l}\text { Счупен чакъл } \\
(\%)\end{array}$ & 27 & 18 & 0 & 6 & 7 & 3 & 18 & 0 & 0 \\
\hline $\begin{array}{l}\text { Форма } \\
\text { (цилиндрична, } \\
\text { сферична) (\%) }\end{array}$ & 63 & 42 & 53 & 34 & 43 & 43 & 47 & 37 & 40 \\
\hline $\begin{array}{l}\text { Форма } \\
\text { (плоскостно } \\
\text { изтеглена, } \\
\text { дисковидна } \\
\text { (\%) }\end{array}$ & 37 & 58 & 47 & 66 & 57 & 57 & 53 & 63 & 60 \\
\hline
\end{tabular}

ладава салтирането. Мразовото изветряне чрез десквамация in situ заобля гранитните блокове до 3-та степен. Каменните реки и морета са значителна част от геоморфоложкия ландшафт на Пирин планина.

Благодарности: Публикуваната статия е част от работата по два проекта: „Природната среда в Пирин в условията на климатични промени“ Договор към ФНИ на МОН №ДН14/6 от 13.12. 2017 г. и „Каменни реки и морета в България - инвентаризация и характеристика“" към УФ „Научни изслевания“ Договор № 80-10-162/ 04. 2019 г.

\section{Литература References}

Caine, N. 1968. The blockfields of northern Tasmania. - In: Australian Natl. Univ., Dept. Geog. Pub. G/6, 127.

Glovnia, M. 1958. Étude de géomorphologie dans la partie sud-ouest de la Rila Planina. - Ann. Univ. Sofia, Fac. géol. et géogr., 51, 3-géogr., 69-174 (in Bulgarian with French abstract).

Glovnia, M. 1962. Étude de la morphosculpture glaciaire dans la partie orientale de la Rila Planina. - Ann. Univ. Sofia, Fac. géol. et géogr., 55, 3-géogr., 3-49 (in Bulgarian with French abstract).

Glovnia, M. 1968. Relief glaciaire et périglaciaire dans la partie méridionale de la Rila Centrale. - Ann. Univ. de Sofia, Fac. géol. et géogr., 61, 2-géogr., 37-69 (in Bulgarian with French abstract).

Marinova, R., I. Zagorčev. 1990. Geological Map of the Republic of Bulgaria on Scale 1:100 000. Map Sheet Razlog. Sofia, Committee of Geology, Dept. of Geophys. prosp. and geol. mapping.

Piirola, J. 1969. Frost-sorted block concentrations in western Inari, Finnish Lapland. - Fennia, 99, 2, 1-35.

Serebrianniy, L. 1980. Laboratory Analysis in Geomorphology. Moscow, Viniti, 152 p. (in Russian).

Sharpe, S. F. S. 1938. Landslides and Related Phenomena. New York, Columbia Univ. Press, 137 p.

Washburn, A. L. 1979. Geocryology: A Survey of Periglacial Processes and Environments. London, Edward Arnold, $406 \mathrm{p}$.

Wentworth, C. K. 1922. A scale of grade and class terms forclastic sediments. - Geology, 30, 377-392. 